\title{
Innovative Approaches in Modeling, Control and Diagnostics of Small Turbojet Engines
}

\author{
Rudolf Andoga*, Ladislav Madarász***, Ladislav Főzö**, \\ Tobiáš Lazar*, Vladimír Gašpar****
}

*Technical University of Košice, Faculty of Aeronautics, Department of Avionics, Rampová 7, 04200 Košice Slovakia, e-mail: rudolf.andoga@tuke.sk

*** Technical University of Košice, Faculty of Aeronautics, Department of Aviation engineering, Rampová 7, 04200 Košice Slovakia, e-mail: ladislav.fozo@tuke.sk

*** Technical University of Košice, Faculty of Informatics and Electrical

Engineering, Department of Cybernetics and Artificial Intelligence, Letná 9, 04200 Košice Slovakia, e-mail: ladislav.madarasz, vladimir.gaspar@tuke.sk

Abstract: The article presents a survey of research and main results achieved in the Laboratory of intelligent control systems of aircraft engines during its five years of existence at the Technical university of Košice celebrating its $60^{\text {th }}$ anniversary. The main areas of scientific interest and results are presented in the fields of innovative approaches in modeling, control and diagnostics of turbojet engines utilizing adaptive and intelligent algorithms. The researched methodologies have been tested and validated on the experimental engine small turbojet engine MPM-20 in laboratory conditions and selected results are presented in the article.

Keywords: turbojet engine; mathematical modeling; intelligent control; diagnostics; artificial intelligence

\section{Introduction}

A turbine engine in its general principle is a complex nonlinear systems with many parameters that are linked with each other through complex thermodynamic bindings. Thermodynamic processes and the need to operate such engines in various conditions presents a vast set of problems that are opened to solutions. Demands on the modern engines lie mainly in efficiency of their operation (output vs. fuel consumption) and safety. The traditional automatic control and diagnostics algorithms are being exhausted and brought to their limits in this area and opens a field of non traditional innovative approaches in this area $[1,2,7]$. The problem with such algorithms that are often non-deterministic in their nature 
or very complex is their operational testing. While in simulation environment such algorithms can produce reliable results, testing in realworld environment with changing conditions may become problematic and expensive in case of failures $[3$, $6,8]$.

The Laboratory of Intelligent Control Systems of Aircraft Engines has been established to deal with the afore mentioned problems at the Technical University. The laboratory has just recently achieved its first milestone of a humble $5^{\text {th }}$ anniversary aiming to become a scientifically important act within the frame of the Technical University of Košice that is celebrating its $60^{\text {th }}$ anniversary this year. This laboratory is a joint venture of three departments: Department of Avionics, Department of Aviation Engineering and the Department of Cybernetics and Artificial Intelligence. The main idea is to design implement and test progressive modeling, control and diagnostic algorithms in realworld conditions on an object of a turbojet engine. As our object the turboshaft engine TS-20/21 was chosen as it was phased out of service and is still in supply from old aircraft in non flying conditions. The engine has been adapted with an exhaust nozzle creating a small turbojet engine MPM-20/21. Such small engine has similar thermodynamic properties and normal sized engine, is affordable to obtain and thus suitable for laboratory experiments with progressive algorithms $[1,10,15,20]$.

The main aim of the laboratory is to do research in three basic areas of cybernetics: modeling, control and diagnostics of complex systems with additional evaluation of efficiency of such research and application of advanced methods in the area of turbojet engines. The obtained knowledge is to be used in modern control systems of small turbojet engines, however it can be expanded to normal sized engines and also other classes of similar complex systems [10, 21, 22].

Apart the mentioned areas of research and results in the last years work has been done in the area of alternative fuels research aimed at bio fuels, ethanol and hydrogenium tested on the object of small turbojet engine. The results have shown usability of such fuels up to certain concentrations (generally around 40\%) and adverse effects on different engine parts were also researched. The other area of tests were carried out to asses the possibility of magnetic field (aura) measurement to evaluate the state of an engine. Pilot experiments were done and have shown some methodological approaches and pilot influence of engine temperature field on manifestation of its magnetic aura. Valid results were also achieved in modeling of temperature channel sensors in order to estimate turbojet engine temperatures infront of the turbine, the results were used in such estimation for the RD-33 engine. All the results from the previous research that are not covered within the presented article have been described in the sources [1, 10, 13, 14]. 


\section{The Laboratory of Intelligent Control Systems of Aicraft Engines}

The Laboratory of intelligent control systems of aircraft engines can be found in the campus of the Faculty of Aviation at Technical University in Košice The laboratory consists of two test rooms and two control rooms specially built for testing of turbo compressor engines. One of the testing and control rooms is shown in Figures 1 and 2. The room contains the object of small turbojet engine MPM-20 with its respective control computer and power supply unit. The other control and testing room contains a small turbojet TJ-100 engine with its control computer [10].

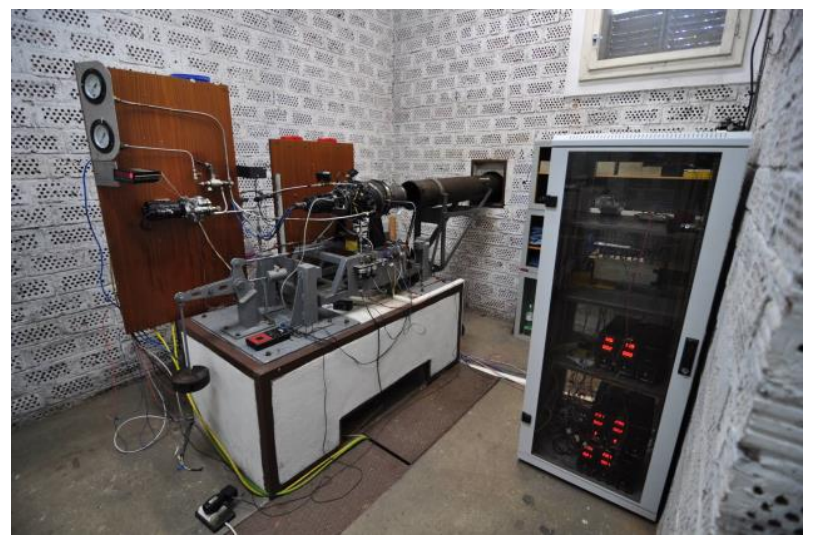

Figure 1

MPM-20 engine in the testing room

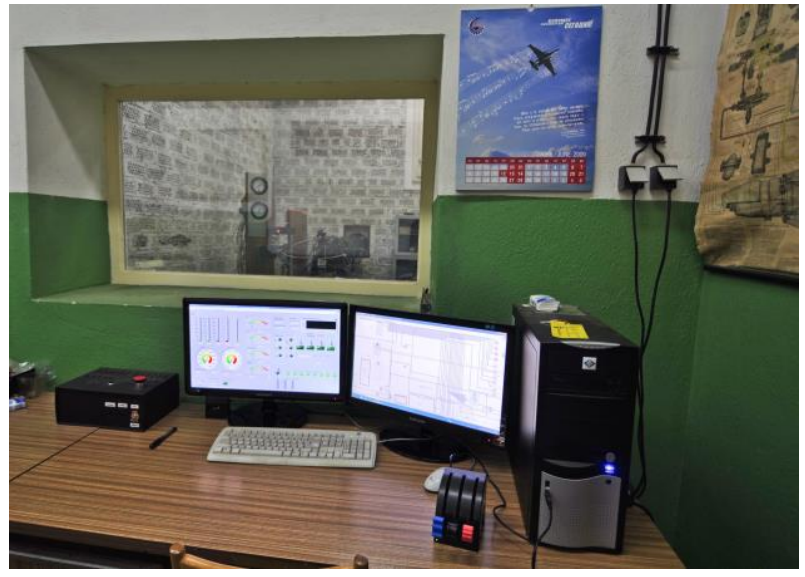

Figure 2

The control room and control computer 
The whole structure of the measurement and control system for the MPM-20 engine is shown in Figure 3. The hydromechanical control and sensing has been transformed into fully digital control of the engine. This allows us to collect all the data from the engine in digital form with specified precision; test and implement models and control aglorithms of the engine [10].

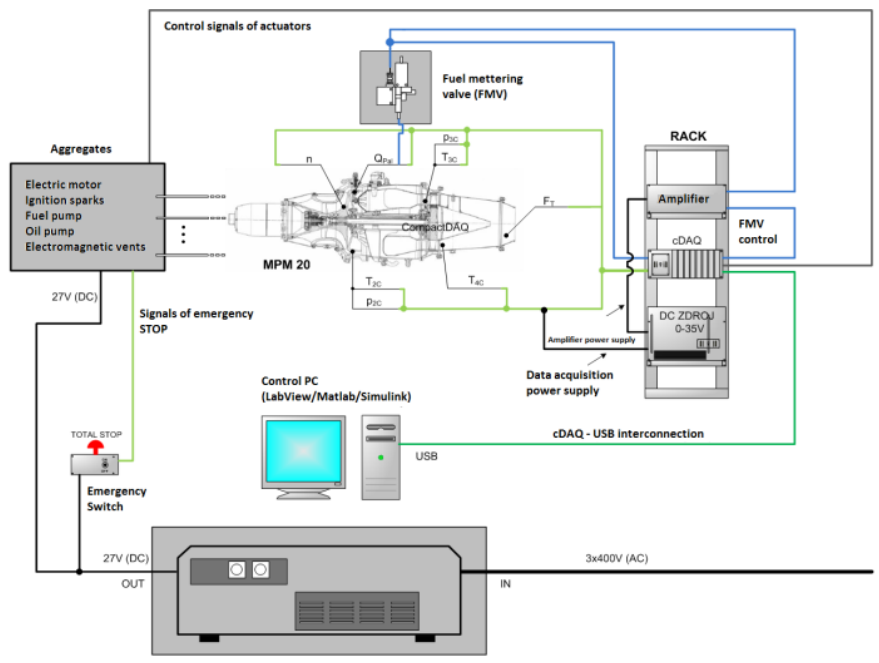

Figure 3

Structure of the engine's measurement systems

\section{Modeling of Small Turbojet Engines}

Aircraft turbo-compressor engines represent multivariable objects of control with existence of crossbindings between inputs and outputs invoked by complex thermo dynamic processes ongoing in inner parts of the engine and dominating load. Except those relations, other can occur by synthesis of control elements that can seriously influence functionality and integrity of the whole mechatronic object (engine and aircraft) $[12,18]$. The active part of the engine is represented by its turbine and the passive part is its compressor. The general aim of multivariable objects control is to obtain optimal quality and stability of the whole control circuit. To obtain this aim it is necessary to build efficient simulation models aimed on control system design. If the control system has to bring a new quality the model used for its synthesis has to also have high quality expressed by its precision compared to real-world data. To obtain this aim a set of non-equal models serving for different purposes has been built. The following chapters illustrate the taken approaches in modeling of the MPM-20 engine for the purpose of its control and diagnostics system design. 


\subsection{A Small Turbojet Engine MPM-20}

In order to build a simulation model of any object, it is necessary to know its properties (dynamic and static) and it structure. The MPM-20 engine in its present form is a one shaft single stream engine with radial compressor and bound combustion chamber with single stage uncooled turbine with fast exhaust geometry. The engine has been modeled in $3 \mathrm{D}$ environment and a render of this model can be seen in Figure 4 [10].

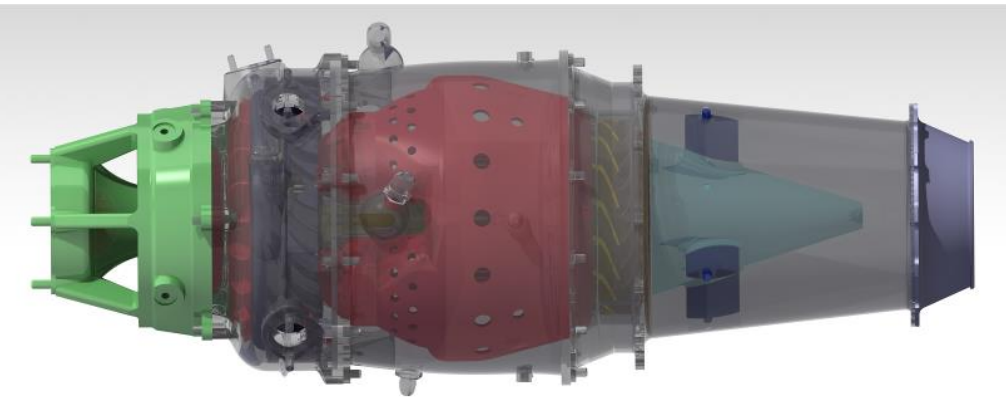

Figure 4

3D model of the MPM-20 engine

\subsection{Analytic Modeling of the MPM-20 Engine}

Static properties of turbojet engines can be calculated under equilibrium engine conditions, dynamic properties can be calculated during non-equilibrium conditions, while utilizing basic physical parameters depedencies in different cut of the engine. Resulting model can be called an analytic one and is used to precisely model thrust, fuel consumption, pressures and temperatures of the engine at different altitudes and velocities in selected cuts of the engine. This approach is called analytic modeling approach and its main benefit is its ability to calculate parameters that cannot be directly measured at conditions that are not obtainable in a laboratory $[4,8,15]$.

While considering a steady operation of the engine, every element of the engine contains same thermodynamic processes. Such operation can be described by [15]:

- Algebraic equations computing the mass flow equilibrium of gasses travelling through all cuts of an engine, control laws and output equations. If such system of equations is sloved in equilibrium operating point, the result will present a steady operational state that an engine stablizies on. 
- Graphic depiction that utilizes expert knowledge of individual constructional parts of an engine (compressor, combustion chamber, turbine, etc) and interactions between them. The graphs can be obtained by experimental measurement or analytic computation with later transformation into a tabular form with description of every regime [4, $16,17]$.

Every operational regime of a turbojet engine has to satisfy the equation of continuity that describes dependencies between air mass flow through compressor the compressor, turbine, combustion chamber and exhaust system $[4,16,17]$ :

$$
Q_{V S}=Q_{k}=Q_{S K}=Q_{T}=Q_{t r}=Q
$$

Also the condition (or assumption) of fast and non-distortive shaft has to be satisfied:

$$
n_{k}=n_{T}=n
$$

where [16]:

Qvs - air mass flow of in the input system,

$\mathrm{Q}_{\mathrm{k}} \quad$ - air mass flow of air in compressor

Q

$\mathrm{Q}_{\mathrm{T}} \quad$ - gass mass flow on the turbine,

$\mathrm{Q}_{\mathrm{tr}} \quad$ - gass mass flow in the exhaust nozzle,

$\mathrm{n}_{\mathrm{k}} \quad-$ speed of the compressor,

$\mathrm{n}_{\mathrm{T}} \quad-$ speed of the turbine.

When solving the equations in equilibrium, thus computing a static analytic model the speed of the engine has to be constant in time $[4,16,17]$.

$$
\frac{d n}{d t}=0
$$

This condition is satisfied when the output of the turbine is equal as power consumed by the compressor and other auxiliary systems of the engine

$$
W_{K C}=\eta_{m} W_{T C}
$$

Where $[4,6,16,17]$ :

$\eta_{m}-$ mechanical effectiveness of the engine,
$\mathrm{W}_{\mathrm{KC}}-$ technical work of the compressor,
$\mathrm{W}_{\mathrm{TC}}-$ technical work of the turbine. 
The complete algorithm that computes all operational points in steady state of a single stream engine can be found in $[4,16]$.

Transitional or non-steady operation of an engine is determined by variable complex thermodynamic processes in each node of a turbojet engine. Operation of the engine in such conditions can be described by a set of non-linear differential equations. Such equations describe non-steady processes in the engine where the operational point of the engine is changing either by fuel flow mettering or flight regime change.

This transitional regime is defined by difference of work of the turbine and power consumption by the compressor. This creates different moments of the turbine $\mathrm{M}_{\mathrm{T}}$ and compressor $\mathrm{M}_{\mathrm{K}}$. In this case, acceleration or deceleration of the engine is defined by the elementar moment equation $[4,16]$ :

$$
M_{T}-M_{K}-M_{a g}=J \frac{d \omega}{d t}
$$

where

$$
\begin{aligned}
& \frac{d \omega}{d t} \text { - angular acceleration, } \\
& \mathrm{J} \quad \text { - moment of inertia of all rotating masses reduced to the shaft of the engine } \\
& \mathrm{M}_{\mathrm{ag}} \text { - moment needed for actuation of aggregates and overcoming of friction. }
\end{aligned}
$$

The speed of the MPM-20 engine can be computed as $\omega=\frac{\pi n}{30}$ and the power output can be computed from the equation $P=M \omega$, after inclusion of mechanical efficiency, the elementar equation of transient operation is created:

$$
P_{T} \eta_{m}-P_{k}=J \frac{\pi^{2}}{900} n \frac{d n}{d t}
$$

In solution of the previous equation, the difference in speed is computed after a preset time step $\Delta \mathrm{t}$ and this algorithm is continuously repeated until the engine settles itself on a new equilibrium point.

Complete analytic model has been computed for MPM-20 engine and implemented in Matlab GUI environment. Such analytic model is called engine deck and can be used for parameters estimation and computation of many non measurable engine characteristics with many variable environmental (air temperature, pressure, humidity, velocity, aerodynamic angles, etc.) and inner parameters (friction, efficiency coefficients, mechanical losses, etc) [4]. 


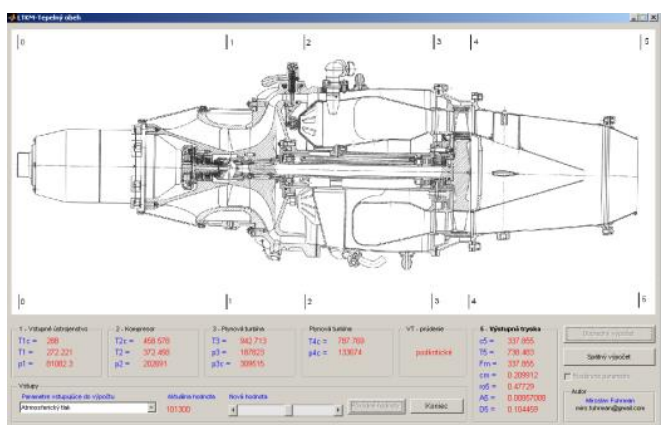

Figure 5

Matlab GUI analytic model

The analytic model will help us in design of complex control algorithms, can be used to design news systems for the engine like variable exhaust nozzle, can be used to calculate operational envelope of the engine and used as a nominal diagnostic model for the engine. Simulations with the analytic model are depicted in the following Figure 6 [4].

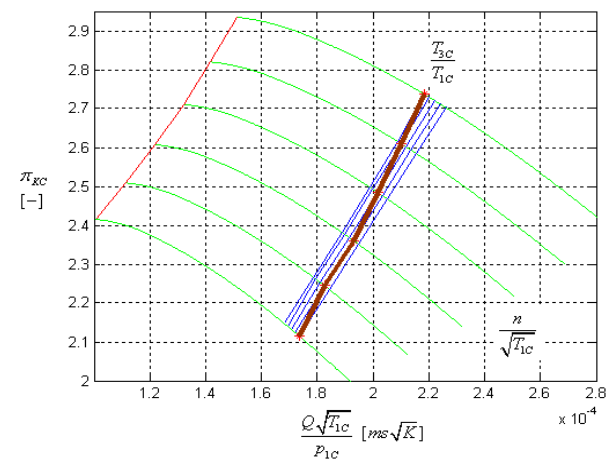

Figure 6

Compressor characteristics as computed by the analytic model

\subsection{Experimental Engine Modeling}

While the analytic models are suitable for computation of many different engine parameters, they are not able to simulate complex dynamic dependencies of individual parameters. Dynamic models used to simulate operation of turbojet engines have a more limited set of parameters and concetrate on complex dynamic dependencies between them. In this case for the MPM-20 engine we will consider exhaust gas temperature - $T_{4 c}$, compressor pressure $-P_{2 c}$, engine speed - $n$ as parameters dependand on fuel flow - $Q_{p a l}$ parameter. Interconnections between the parameters however are not stationary, so the model changes structure in different 
operating conditions, it can be stated that operating point will be defined as a functional of the following parameters [10]:

$$
O_{p}=f\left(Q_{p}, N_{1}, T_{4 c}, P_{2}, t\right)
$$

Because the functional (8) defines a complex multidimensional nonlinear space, it is very difficult to create a qualitative dynamic model of such functional. To solve this problem a methodology of situational modeling is proposed. This means to decompose the model into certain operating regions where we can consider the structure of the model to be stationary. By such decomposition we can obtain a set of models defining the operation of the engine [10].

$$
O_{p i}=f_{i}\left(N_{1}, T_{4}, P_{2}\right), i=1 \ldots n
$$

where $n$ is the situational frames count. Decomposition can be done by means of using expert knowledge or clustering (classification algorithms). To exclude time from the model we propose an intelligent selector that will select appropriate model for the given conditions. The architecture of the model is shown in Figure 7 with decomposition of the model into three structurally different submodels representing start-up, steady operation and shutdown of the engine.

Inputs of the classifier are defined by outputs of individual models while the total input to the model is only its fuel flow parameter - however other parameters (like environmental parameters can be used to improve selection of the active situational frame. The gating signal from the classifier can be defined as [10]:

$$
O_{u}=\left[x_{1}, \ldots, x_{n}\right]
$$

where $n$ is the number of situational model frames and $x_{i}=\{0 ; 1\}$, in our case $n=3$. So the classifier switches

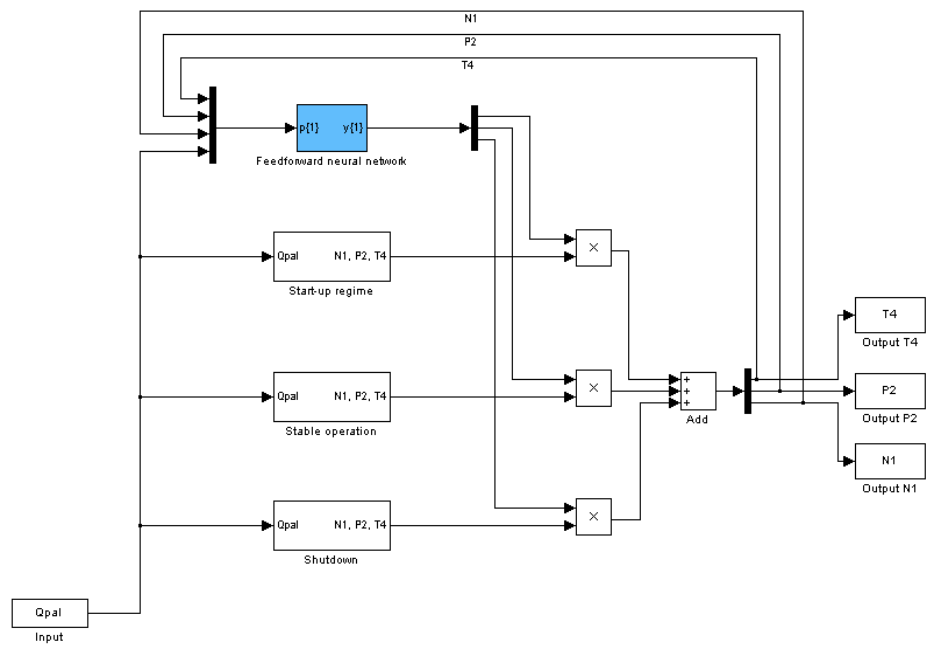

Figure 7

The structure of situational control model implemented in Matlab/Simulink 
The classifier neural network utilizes state variables produced by the individual models, while the input parameter is only the fuel flow. The situational classifier will have its output in the following form:

$$
O_{u}=\left[x_{1}, \ldots, x_{n}\right]
$$

where $n$ is the number of situational model frames and $x_{i}=\{0 ; 1\}$, in our case $n=3$.

The models were tested separately with fuel supply inputs measured during different engine runs. Startup model utilizes feedforward neural networks with input time delays composed of two hidden layer and is trained by SCG algorithm [15]. The equilibrium operational state model is composed of three models using Takagi Sugeno (TSK) fuzzy inference systems to model individual parameter dependencies and the shut-down model uses neural networks of identical structure as the startup model trained with other data. Results of the average errors during those 15 runs show very good results as illustrated in Table 1, where MAE is mean absolute error averaged through 15 runs, MAAE is maximum absolute average error from those 15 runs and the errors are also expressed in percents (MAPE, MAAPE).

Table 1

A summary of the MPM-20 model simulations

\begin{tabular}{|l|l|l|l|l|}
\hline Parameter & $\mathrm{MAE}_{\mathrm{i}=1 \ldots 15}$ & $\mathrm{MAAE}_{\mathrm{i}=1 \ldots 15}$ & MAPE $_{\mathrm{i}=1 \ldots 15}$ & MAAPE $_{\mathrm{i}=1 \ldots 15}$ \\
\hline $\mathrm{N}(\mathrm{rpm})$ & 67 & 275 & 0.14 & 0.61 \\
\hline $\mathrm{T}_{4 \mathrm{C}}\left({ }^{\circ} \mathrm{C}\right)$ & 13 & 56 & 1.1 & 2.7 \\
\hline $\mathrm{P}_{2 \mathrm{C}}$ (at) & 0.065 & 0.071 & 1.7 & 1.88 \\
\hline
\end{tabular}

The maximum absolute percentage error is at $1.7 \%$ for $\mathrm{P}_{2 \mathrm{C}}$ parameter and the maximum percentage absolute error for $\mathrm{T}_{4 \mathrm{C}}\left({ }^{\circ} \mathrm{C}\right)$ is at $2.7 \%$ and this shows that the model produces a very accurate dynamic prediction in its all operational states.

\section{Intelligent Engine Control Systems}

Methods of artificial intelligence increase the quality of control processes. However this quality is conditioned only by careful analysis of the system they are applied to [12, 18, 19]. At low control level (as by control of turbojet engines), we deal mostly with raw data - therefore approaches utilizing pricniples of subsymbolic artificial intelligence will be used in design of intelligent full authority digital engine control (iFADEC). From modeling and selected preliminary control systems design we are aiming mainly at [21, 22]:

- neural networks,

- fuzzy inference systems. 
These approaches are to be combined also with traditional control approaches into an adaptive hybrid control algorithm scheme utilizing the concept of situational control $[12,19]$. The concept is shown in the framework architecture in Figure 8 with four controllers for different situational states the controlled engine can find itself.

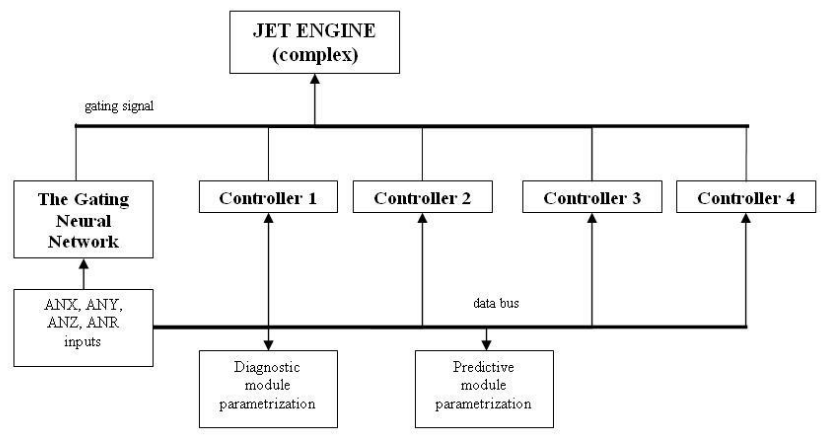

Figure 8

The structure of situational control model implemented in Matlab/Simulink

The basic concept of the situational control system is to decompose all operational states of an engine into time spaced situational frames while every situational frame would have at least one corresponding control algorithm assigned to it. Special attention is aimed at handling of critical areas of operation.

In the concept we propose dynamic (time delayed) neural network in the form of situational classifier with a corresponding set of controllers to handle individual situational frames. In design the concepts of traditional situational control and formatter control of complex systems were used $[2,14]$. The resulting physical architecture including analyzers of input (X), state (Z), output (Y) and desired (R) parameters is shown in the Figure 9

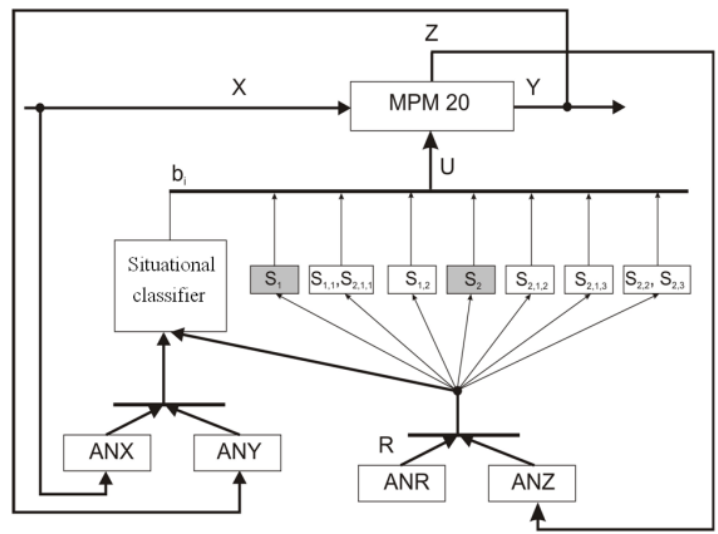

Figure 9

The structure of situational control model implemented in Matlab/Simulink 
Blocks designated as $S_{i, j, k}$ represent controllers for different situational frames, where the system is decomposed into three basic frames horizontally and further decomposed into three levels vertically.

The primary situational decomposition of the engine states is shown in Figure 10 $[1,10]$.

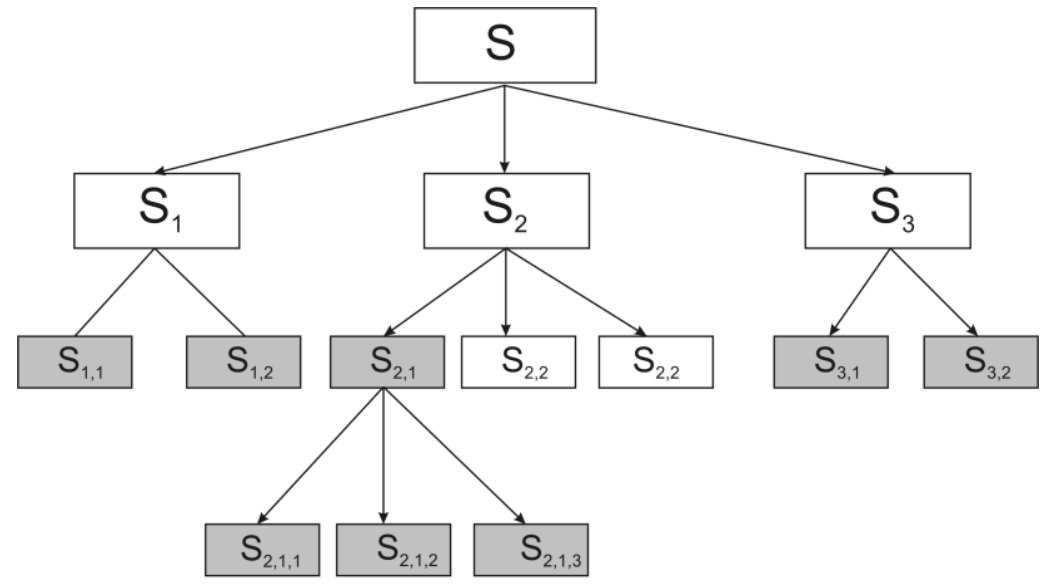

Figure 10

Decomposition of situational frames into a situational graph [10]

The blocks in the figure 10 have the following meaning $[1,10]$ :

$S_{1}-$ startup of the engine:

$\underline{\mathrm{S}}_{1,1}$-temperature problem, $\underline{\mathrm{S}}_{1,2}$-pressure $\mathrm{P}_{2 \text { c problem }}$

$\mathrm{S}_{2}-$ steady state of operation:

$\underline{S}_{2,1}$ - steady atypical state:

$\underline{S}_{2,1,1}$ : low compression, $\underline{S}_{2,1,2}$ - low fuel flow, $\underline{S}_{2,1,3}$ - unstable speed,

$\mathrm{S}_{2,2}-$ acceleration,

$\mathrm{S}_{2,3}-$ deceleration

$\mathrm{S}_{3}-$ shutdown

$\underline{S}_{3,1}-$ stall of the engine

$\underline{S_{3,2}}$ - error by run-down

The grey blocks in Figure 10 represent atypical operational conditions with specialized control algorithms and approaches to handle them. 


\section{Small Turbojet Engine Diagnostic/Backup System}

The small turbojet engine MPM-20 also serves us for testing purposes of redundant backup/diagnostic systems. The designed architecture of such system has been tested for a single engine parameter the speed of the engine. This parameter is crucial as it defines thrust and power output of the engine and is the primary controlled parameter. The main way to measure the speed of the engine is the optical sensor, while the other ways are synthetic model values [10, 13]:

- $\quad$ successive integration dynamic model,

- a neural network.

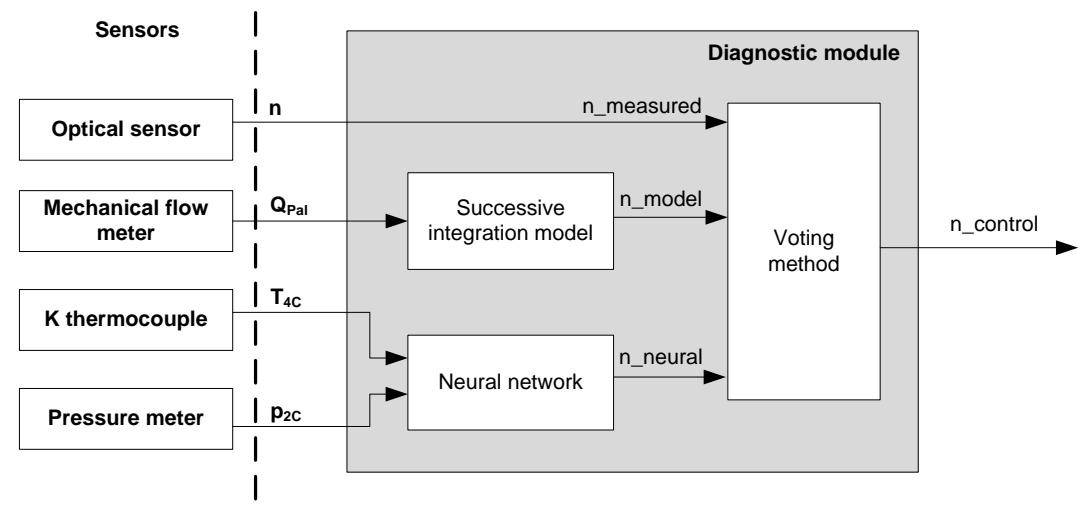

Figure 11

The structure of the diagnostic module

The basic designed architecture of a simple single parameter diagnostic system is shown in the figure 11 . Reliability of the model is secured through independence of input parameters while utilizing virtual engine models to compute the speed. There are two basic errors that can occur with the optical sensor [10,13]:

- A random value - caused by electro-magnetic environment disturbance,

- Sensor failure - it can be caused by a loss of power, loss of communication channel, loss of reflex area on the compressor blade.

The designed backup/diagnostic system is utilizing adaptive voting majority methods and its principal implementation is shown in Figure 12. The system can exclude faulty speed computation/measurement from its output and can also indicate its own total failure utilizing precise dynamic engine models. The resulting speed of the engine is represented by the average value of all means of speed computation/measurement $\mathrm{I}_{\mathrm{c}}$. 


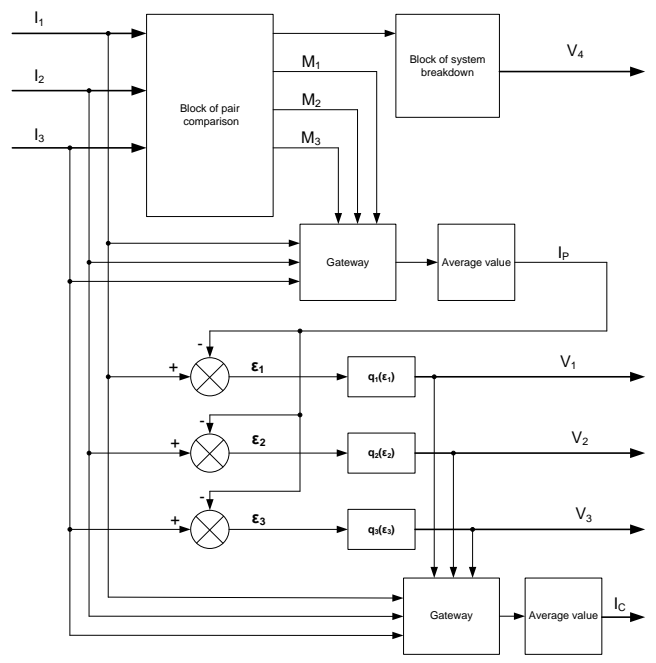

Figure 12

The structure of the diagnostic module

The designed diagnostic/backup system has been experimentally tested with the MPM-20 engine during its operation within running on speed of 43500 RPM. During the test all input had simulated errors; this is shown in Figure 13. During the test even real error of the optical sensor occurred at time of 30 seconds. The output of the diagnostic/backup system however was not influenced and has operated as desired. Further expansion of the system will lead into a highly redundant diagnostic/backup system utilizing the presented concept, where all important engine parameters (temperatures, pressures, fuel flow, thrust) will be mutually backed up, thus creating a highly redundant backup system.

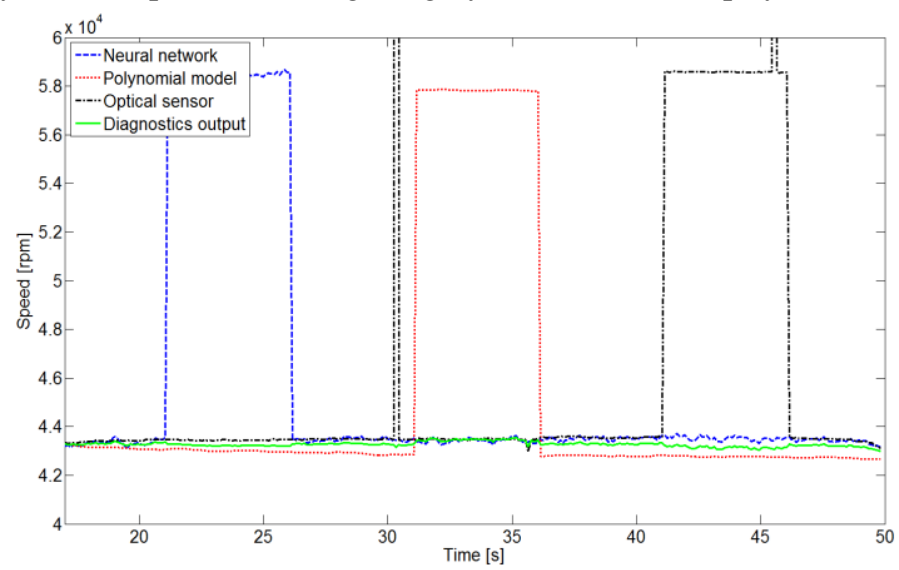

Figure 13

Diagnostic/backup system test results 


\section{Physical and Mathematical Modeling in the Research of the Efficiency of Technical Systems}

A special emphasis has been recently put on evaluation of efficiency of research and object operation in the Laboratory of intelligent control systems of aircraft engines. A methodology for efficiency evaluation is being developed in conditions of the laboratory on the object of a small turbojet engine, whereas the resulting knowledge is generalized for complex technical systems [11]. Efficiency of a complex technical systems is estimated according to characteristics that are used to evaluate its utility parameters. The efficiency is considered one of the characteristic parts of the utility that brings up the physical and economical character. The testing procedure in each phase of efficiency evaluation is always connected to analysis [9]. Simple illustration of this process is depicted in Figure 14 [11].

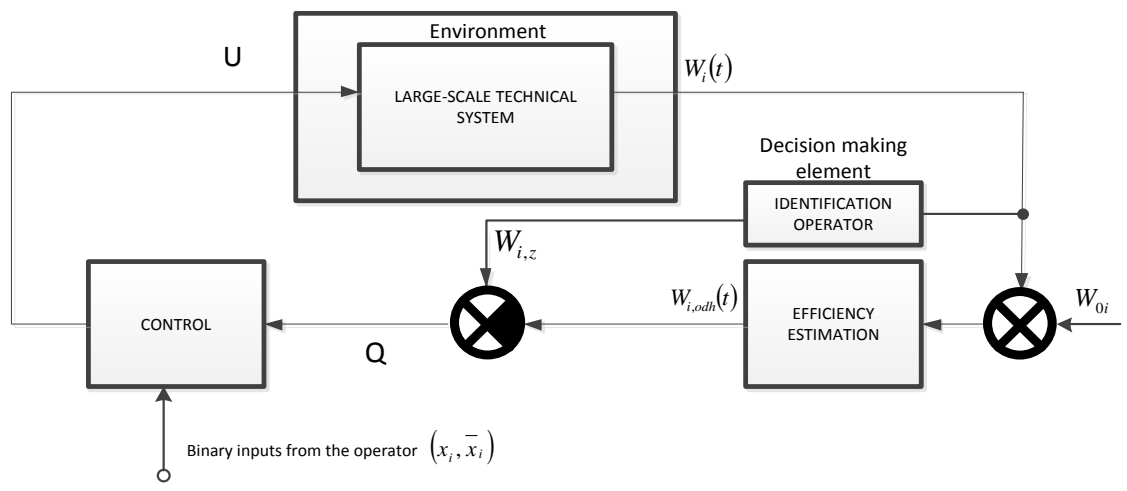

Figure 14

Efficiency estimation using feedback

\section{Description:}

$W_{0 i}$ - starting value of the efficiency in the i-th phase (time independent),

$W_{i}(t)$ - real-time value of the efficiency (reached ecciciency in i-th phase),

$W_{i, o d h}(\mathrm{t})$ - estimation of efficiency in i-th phase,

$W_{i, Z}$ - requested efficiency value (time independent), after i-th phase,

$\mathrm{U}$ - efficiency control.

According to Fig. 14 it is possible to evaluate the output effect, which quantifies reached efficiency in $\mathrm{i}$-th phase, using the following formula:

$$
Q_{i}=1-\left(W_{i, Z}-W_{i, o d h}\right)
$$


However, this formula has only limited effect because it disregards expenses, connected with reaching the requested efficiency. Expenses may be represented by various parameters. Usually they are expressed as required time, required wages, required new knowledge, financial expenses for test evaluation, etc [9]. It is possible to consider expenses as the part of the efficiency function is we consider the general efficiency formula:

$$
E=\frac{Q}{S},
$$

where:

E - general efficiency criterion,

$\mathrm{Q}$ - output system effect,

$\mathrm{S}$ - expenses needed to reach the output effect.

Both methods reflect the iterative character of testing that is carried out according to detailed theoretical planning of each experiment, its methods and expectations. The iterative process of continuous efficiency increase of the experimental identification can be observed in Figure 15.

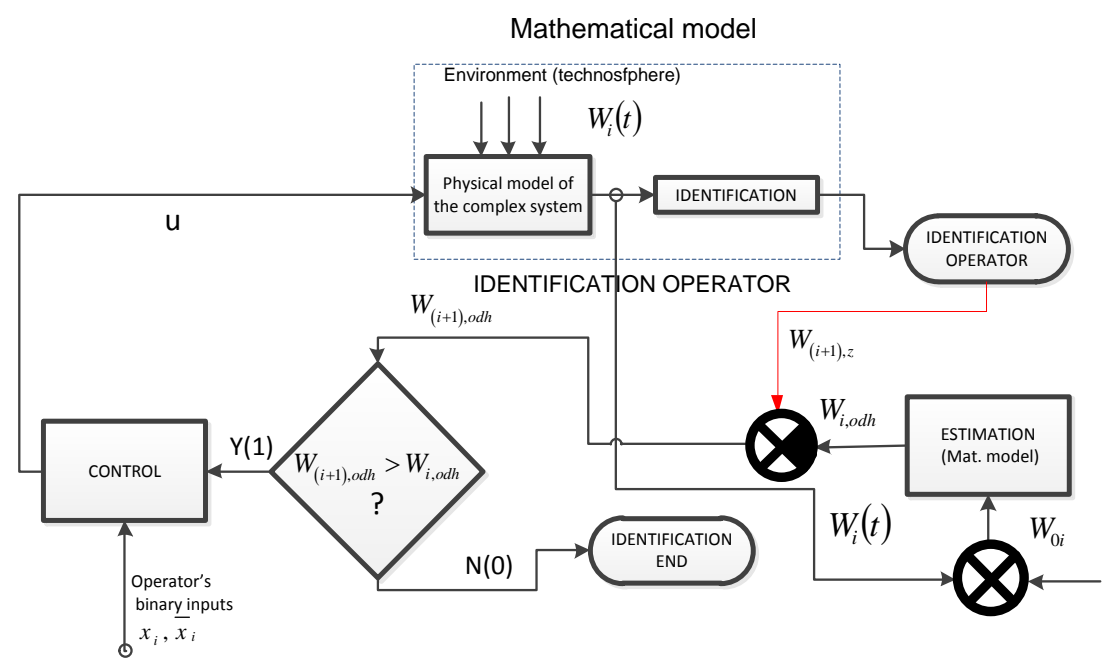

$W_{(i+1), Z^{-}}$predicted efficiency value (aposterior information is efficiency independent).

Figure 15

Complex system identification process with the possibility of efficiency increase 


\section{Conclusions}

The article overviewed the main approaches and ideas developed in the Laboratory of intelligent control systems of aircraft engines. The scope of research in the laboratory is aimed at progressive methodologies applicable in modeling, control and diagnostics of jet engines but the ideas have also potential to be generalized for other classes of large scale systems. Obtained results show that application of modern adaptive methodologies can bring new quality, reliability and efficiency of operation of such systems. Research in the laboratory is aimed at modular designs that can utilize different control concepts combining the adaptive and classical approaches combined in such structures.

\section{Acknowledgement}

The work presented in this paper was supported by VEGA, Grant Agency of Ministry of Education and Academy of Science of Slovak Republic under Grant No. 1/0298/12 - "Digital control of complex systems with two degrees of freedom" and grant No. 1/1117/11 - "Integration of automatic flight control algorithms with control algorithms of aircraft turbocompressor engines". The work presented in this paper was also supported by KEGA under Grant No. 018TUKE4/2012 - "Progressive methods of education in the area of control and modeling of complex systems object oriented on aircraft turbo-compressor engines.

\section{References}

[1] Adamčík, F., Bréda R.: The Determination of Input Parameters for NonContact Temperature Measurement of the LTJE, In: Acta Avionica. Roč. 13, č. 22 (2011), s. 77-80. - ISSN 1335-9479

[2] Beneš, J. (1974), Teorie systémů (řizeni komplexů)(Theory of systems), 200 pp. Academia, nakladatelství ČSAV, 1974, Czech. Rep.

[3] Boyce P. Meherwan: Gas Turbine Engineering Handbook, Third Edition, Elsevier 2006, 935 pp., ISBN 0-88415-732-6

[4] Főző, L.(2008). Use of Mathematical Model of Steady and Nonsteady Operation of MPM20 Turbojet Engine by Design of Anytime Control Algorithms (in Slovak), Dissertation thesis, Dept. of Cybernetics and AI, Faculty of Electrical Engineerin and Informatics, Technical University of Košice, 144 p., September 2008, Slovakia

[5] Harris, Ch., Hong, X., Gan, Q. (2006) Adaptive Modelling, Estimation and Fusion from Data, Springer, ISBN 3-540-42686-8, p. 323, 2006

[6] Jaw C. L., Mattingly D. J.: Aircraft Engine Controls Design, System Analysis, And Health Monitoring, American Institute of Aeronautics and Astronautics, 2009, p. 361, ISBN 978-1-60086-705-7

[7] Jonathan S., L., Turso, J., A., Shah, N., Sowers., T., S., Owen, K., A. (2005) A Demonstration of a Retrofit Architecture for Intelligent Control and Diagnostics of a Turbofan Engine, NASA/TM -2005-214019, USA 
[8] Kulikov G., Thompson A.: Dynamic Modelling of Gas Turbines Identification, Simulation, Condition Monitoring and Optimal Control, Springer 2004, 337 p., ISBN 1852337842

[9] Krineckij, E., Aleksandrovskaja: Letnye ispytancija sistem upravcenija letatelnymi apparatami, MOSKVA, Mašinostoje 1975, p. 46

[10] Lazar, T., Madarász, L. (Eds.): Inovativne výstupy z transformovaného experimentálneho pracoviska $s$ malým prúdovým motorom (Inovative Outputs from the Transformed Experimental Laboratory with a Small Turbojet Engine). elfa, s.r.o. Košice, 348 p. ISBN 978-80-8086-170-4 (2011)

[11] Lazar, T., Madarász, L., Gašpar, V.: Procesná analýza odhadu efektívnosti identifikácie MPM s inteligentným riadením (Process analysis of efficiency estimation of MPM identification with intelligent control), elfa s.r.o, ISBN 978-80-8086-200-8, p. 160, 2013

[12] Linke-Diesenger, A. (2008). Systems of Commercial Turbofan Engines: an Introduction to Systems Functions, Springer, ISBN 978-3-540-73618-9

[13] Madarász, L., Andoga R., Főző, L., Lazar. T.: Situational Control, Modeling and Diagnostics of Large Scale Systems, In: Towards Intelligent Engineering and Information Technology, Rudas I. J., Fodor, J., Kacprzyk, J. (Ed.), p. 153-164., ISBN 978-3-642-03737-5, Springer-Verlag, Berlin.'

[14] Madarász, L.: Metodika situačného riadenia a jej aplikácie (Methodology of situational control and its applications), 212 p. ISBN $80-88786-66-$ 5, Elfa Košice, 1996

[15] Moller, M. F. (1993) A Scaled Conjugate Gradient Algorithm for Fast Supervised Learning, Neural Networks, Vol. 6, pp. 525-533, 1993

[16] Považan J (1999): Konštrukcia matematických modelov leteckých turbokompresorových motorov (Construction of Mathematic models of Aircraft Engines), VLA M.R.Š. v Košiciach, ISBN 80-7166-030-2, Slovakia

[17] Ružek, J., Kmoch, P. (1979) Teorie leteckých motoru I. (Theory of Aircraft Engines), 373 pp, 1979, Czech Rep.

[18] Wiseman, M. (2005). Intelligent Engine Systems, NASA CR/-2005213964, USA

[19] Tar, J. K., Rudas, I. J., Kósi, K., Csapó, A., Baranyi, P.: Cognitive Control Initiative. $3^{\text {rd }}$ IEEE International Conference on Cognitive Infocommunications. December 2-5, 2012, Košice, Slovakia. pp. 579-584, ISBN 978-1-4673-5185-0

[20] Chebre M., Meroufel A., Bendaha Y.: Speed Control of Induction Motor Using Genetic Algorithm-based PI Controller, Acta Polytechnica Hungarica, Vol. 8, No. 6, pp. 141-153, 2011 
[21] Precup R.-E., Tomescu M.-L., Petriu E. M., Preitl S., Dragos C.-A.: Stable Design of a Class of Nonlinear Discrete-Time MIMO Fuzzy Control Systems, Acta Polytechnica Hungarica, Vol. 9, No. 2, pp. 57-76, 2012

[22] John, S., Pedro J. O.: Hybrid Feedback Linearization Slip Control for AntiLock Braking System, Acta Polytechnica Hungarica, Vol. 10, No. 1, pp. 8199, 2013 